\title{
INFANT MORTALITY - GYNAECOLOGICAL AND UNEMPLOYMENT ASPECTS IN OPOLE PROVINCE, POLAND
}

\author{
Andrzej Tukiendorf ${ }^{1}$, Michał Łasocha ${ }^{2}$, Grzegorz Krasowski ${ }^{3}$, Ewa Orska ${ }^{2}$, Aleksandra Porębska ${ }^{1}$ \\ ${ }^{1}$ Opole University of Technology, Opole, Poland \\ ${ }^{2}$ Gynaecological-Obstetric Hospital in Opole, Poland \\ ${ }^{3}$ Provincial Hospital in Opole, Poland
}

\begin{abstract}
SUMMARY
In the study the results of the relation between infant (neonatal + post-neonatal) mortality and the gynaecological and unemployment factors are presented. The findings are based on Bayesian modelling and indicate the possible influence of the unemployment situation on mortality, whereas no correlation was found as regards access to the availability of gynaecological health care. The main conclusion is that elevated unemployment which could be referred to a poor socioeconomic situation (amongst other factors) may force pregnant women to pay more attention to improving their life conditions, than to sufficient medical controlling.
\end{abstract}

Key words: infant mortality, relative risk, gynaecological doctor ratio, unemployment, WinBUGS

Address for correspondence: A. Tukiendorf, Opole University of Technology, ul. Mikołajczyka 5, 45-271 Opole, Poland.

E-mail: antu@po.opole.pl; calisto1411@yahoo.com

\section{INTRODUCTION}

Infant deaths are mainly attributable to the following causes: pre-maturity, congenital malformations, infections, and sudden infant death syndrome. These death rates (among others) are usually used in epidemiology to determine the health status in regions as well as to correlate with some ecological (health care or socioeconomic) variables.

The factors predisposing to neonatal (to 27 days of life) and post-neonatal (28 to 364 days) deaths have been the subject of intense study for many years. Moreover, the analysis of infant mortality data provides an opportunity for developing preventive strategies to improve this indicator of the population's health.

\section{Pre-maturity}

It is stated that pre-maturity alone is the chief cause of infant death and for very underweightbabies at birth, pre-maturity related conditions accounted for nearly $70 \%$ of the deaths (1). However, different statistics are given in scientific reports. For example, pre-maturity related conditions accounted for (1) $37.5 \%$ of all deaths. In turn, in the study (2) these causes of infant deaths were responsible for $11 \%$ deaths only.

Premature infant fatality rates vary inversely with the birth weight (3). Infections or inflammatory disease may contribute to ethnic differences due to the risk of premature delivery (4). It was found that premature mortality was the greatest in rural counties (in a model predicting $55 \%$ of variation across counties, community structure factors tended to contribute more to this than the availability of medical care). Moreover, the proportions of female-headed households and Afro-american population were the strongest predictors, followed by variables measuring low education, American Indian population, and chronic unemployment (5). Generally it has been established that chances of premature infants for survival will be increased largely by prolonging their foetal existence (3).

\section{Congenital Malformations}

Congenital malformations are established as the second leading cause of infant death. They showed a 20\% (2, 6), $50 \%$ (7), and $59 \%$ (8) range in mortality rates, respectively.

Socioeconomic trends of higher risks in lower social classes have been reported in the literature for many non-chromosomal congenital malformations including cardiac defects, cardiac septa, digestive system, neural tube and multiple malformations. A comprehensive review on these reports can be found in the article by Vrijheid et al. (9). However, the authors stress that no other studies have reported socioeconomic variation in multiple congenital anomalies. Besides they found a decreasing risk with increasing deprivation for all chromosomal malformations and Down's syndrome, resulting mainly from differences in the maternal age distribution between social classes that, in turn, may result from socioeconomic related environmental exposures differentially affecting intrauterine survival of foetuses with chromosomal anomalies (9). However, since the aetiology of congenital anomalies is still largely unknown, larger studies are needed to confirm these findings and to explore their aetiological implications. Moreover, the range of risk factors which could mediate the impact of socioeconomic status on the prevalence of congenital anomalies is wide and includes nutritional factors, lifestyle, environmental and occupational exposures, access to 
and use of health services, parity and maternal age, and ethnic origin. Thus, it is stressed, that progress in clinical management, together with policies for increased access to prenatal diagnosis, may result in considerable reductions in early neonatal mortality [of e.g. congenital heart disease (10)]. Hence, diagnostic measures together with the use of genetic counselling, screening, and social education still represent the major preventive efforts that may contribute to a significant reduction in neonatal and postneonatal mortality caused by congenital malformations.

\section{Infections}

Infection is the acute or associated cause of death causing $9 \%$ of the total post-neonatal mortality (2), $10 \%$ reported by (7), and $12 \%$ by (8).

There is a winter peak of deaths from infection, the highest number occurring in December (21 \%) (11). However, infants born in the months of October, November, and December were at decreased risk for viral gastroenteritis, perhaps because of the seasonal pattern of rotavirus infection, the duration of maternal antibody, or the presence of rotavirus IgA in human milk (12).

Deaths caused by infection were also associated with deprivation (13). Half of the deaths from infection occurred in crowded households ( $>1$ adult or child per room) which is also a significant factor (OR = 10.37; $95 \%$ CI: 1.08-99.59) (11). However, the association of infection mortality in infants with socioeconomic status variables has not always been ascertained (14).

In addition, breastfed children have a decreased risk of postneonatal death in the United States, although infectious diseases, those most plausibly prevented by breastfeeding, no longer contribute substantially to post-neonatal mortality. Is it plausible that breastfeeding protects not only against infectious disease mortality, through maternal immune enhancing mechanisms, but also against sudden infant death syndrome, accidental death, and others (15).

It has also been found that there is a marked dose-response effect related to birth weight infection deaths. For example, a study of (16) demonstrated that low birth weight is a significant risk factor for diarrhoeal mortality in the United States.

Moreover, low doses zinc supplementation to gestational age infants may substantially reduce infectious disease morbidity and mortality (14). With the demonstration that vitamin A supplementation reduces child mortality (17), there has been increasing recognition of the importance of nutrient deficiencies and their role as determinants of infectious diseases. Therefore, it is becoming clear that a large portion of the risk of infectious disease morbidity and mortality attributed to malnutrition may be the result primarily of deficiency of a few critical micronutrients (14).

\section{Sudden Infant Death Syndrome}

A concise and very comprehensive review about sudden infant death syndrome (SIDS) is given (11). However, a number of studies on SIDS and risk hypotheses about its aetiology can be found in scientific literature, i.e. pointing to e.g. concepts of multifactor causation with the interaction of risk factors (and varying probabilities) (18), or maternal risk factors that involve severe anaemia (19). Genetic alterations that may cause SIDS or gene polymorphisms that may predispose infants to the syn-drome cannot be neglected as well (20). Some sources report that there is a highly significant association between $H$. pylori ure $C$ and $\operatorname{cag} A$ genes in the stomach, trachea, and lung in cases of SIDS (21). Furthermore, for infants of well educated mothers, the risk of SIDS is significantly lower than in case of less educated mothers (22). Findings also indicate that poor postnatal weight gain may be independently associated with an increased risk of SIDS (23). Nevertheless the majority of research findings suggests that the aetiology of neonatal and post-neonatal mortality from SIDS is heterogeneous, and it is a cause of about $8 \%$ of all infant deaths (6) ranging from 0.77 (11) to 1.20 deaths per 1000 live births (24). Although in different studies many of the epidemiologic features that characterize SIDS remain generally consistent to each other (11).

\section{All Groups of Death Combined}

Unmarried women had a significantly decreased risk of neonatal death (OR: 0.74) and a significantly increased risk of postneonatal death (OR: 1.40) when compared with married women. What is more, multiparous women have a higher risk of infant death due to inadequate use of prenatal care. The strongest predictors of neonatal and post-neonatal death are infant birth weights of $<2499 \mathrm{~g}$ and gestational age of $<33$ weeks (4).

Birth weight is the single most important determinant of infant survival in developing countries. The low birth weight is estimated to be an underlying risk factor in $>70 \%$ of prenatal deaths, $90 \%$ of neonatal deaths, and $50 \%$ of infant deaths. Unlike in developed countries, where preterm birth is the main cause of low birth weight (LBW), in developing countries most LBW infants are small for gestational age (14).

An increase of one primary care doctor per 10,000 population was associated, on average, with a $2.5 \%$ reduction in infant mortality. Moreover, primary care is associated with reduced infant mortality, primarily through better maternal health and lower post-neonatal mortality (25).

Dramatic changes in income in New Zealand possibly translated into increasing relative inequality in child mortality by income, but not by education or occupational class (26). Poorer socioeconomic conditions that native American families experience including problems of alcoholism, unemployment, and family disorganization contribute to a high rate of post-neonatal mortality (27).

\section{AIM OF THE STUDY}

The aim of this study is to verify the given facts with the results obtained using a particular data set of infant mortality in relation to health care and a chosen socio-economic factor.

It is of note, however, that in this relatively small province of Opole, Poland, the neonatal and paediatric health care cannot be considered in the geographical dimension since in case of life threat infants are carried out to the central Infant Pathology Unit located in the provincial capital (city of Opole). Therefore, in the aspect of infant health care only the gynaecological care (doctor ratio) can be analyzed statistically. In addition, the influence of the unemployment situation in the region was taken into account. In the paper, first the information on the research material and the chosen method are given. Then, spatial patterns of the mortality and correlation statistics are presented. Finally, the discussion of the achieved findings is conducted. 


\section{MATERIALS}

The data on live births in the consecutive years 1999-2003 (Table 1) were provided by the Centre of Public Health in Opole. The referred female population in reproductive age (16-39) were taken from the regional Bureau of Statistics in Opole.

Table 1. Live births in Opole province in the consecutive years 1999-2003

\begin{tabular}{|c|c|}
\hline Year & Live births \\
\hline 1999 & 9723 \\
\hline 2000 & 9541 \\
\hline 2001 & 8930 \\
\hline 2002 & 8452 \\
\hline 2003 & 8147 \\
\hline
\end{tabular}

From Table 1, a monotonic decrease of live births across the analyzed period is observed (approximately 1\% yearly).

The data on infant (neonatal and post-neonatal) mortality registered in the province in the years 1999-2003 (registered according to the WHO) originated from the Centre of Public Health in Opole. The numbers of infant deaths - distinguished by causes (calculated per 1000 of all live births) in the analyzed years (excluding 6 crime victims in the period) are shown in Table 2.

Table 2. Numbers of infant deaths by causes (1999-2003)

\begin{tabular}{|l|c|c|}
\hline Cause of death & Number of cases & $\begin{array}{c}\text { Mortality per } \\
1000 \text { live births } \\
\text { per year }\end{array}$ \\
\hline Congenital malformation & 96 & 2.14 \\
\hline Prematurity & 66 & 1.47 \\
\hline Infection & 28 & 0.63 \\
\hline Sudden infant death syndrome & 40 & 0.89 \\
\hline
\end{tabular}

From Table 2 it can be seen that congenital malformations and premature deaths are the leading causes of infant death in the region in the analyzed quinquennium, while the infection stands for the lower infant deaths.

Information on gynaecologists, i.e. numbers of medical doctors in particular counties of the province of Opole that were active in the year 2001 was taken from the Regional Doctoral House in Opole. The data were aggregated into the counties since most of the gynaecological clinics are located in the seats of local authorities. A spatial distribution of care doctor ratio in a reference to women aged 16-34 in the particular counties (2001) is presented in map in Fig. 1.

In the map showed in Fig. 1, different ratios of the gynaecological care are observed, though the Prudnik county and the

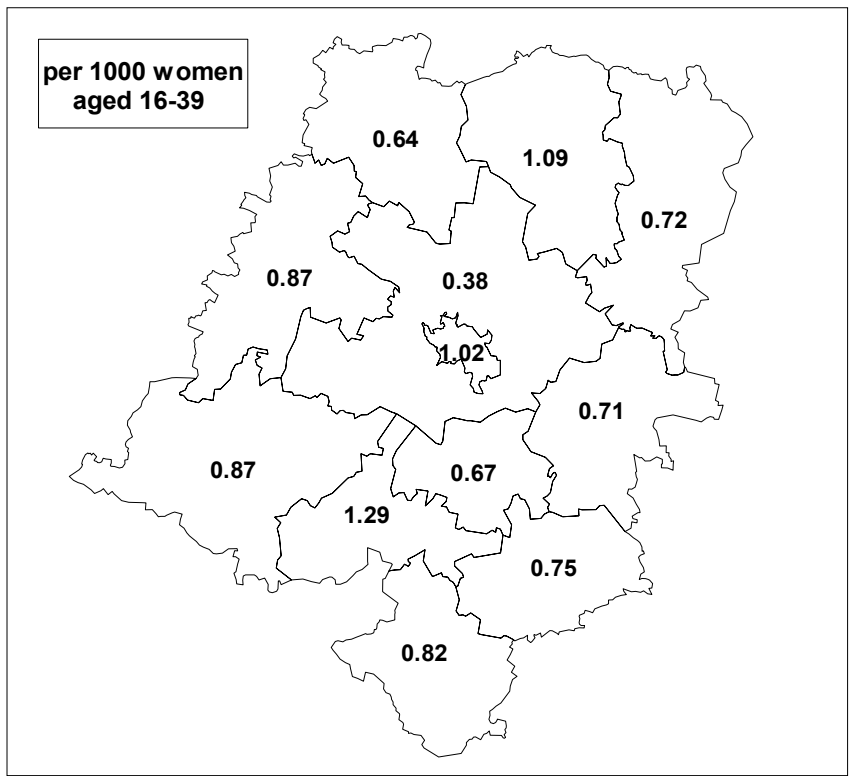

Fig. 1. Number of gynaecologists per 1,000 women in reproductive age.

capital of the region are characterized by the densest care supply, respectively.

The unemployment rates in all the communes of Opole province in 2001 were taken from the Bureau of Statistics in Opole. The spatial distribution of the socioeconomic variable is presented in Fig. 2.

The unemployment pattern showed in Fig. 2 demonstrates that highest rates are observed in the western part of the province of Opole, while the lowest ones are in administrative units located in the east of the region.

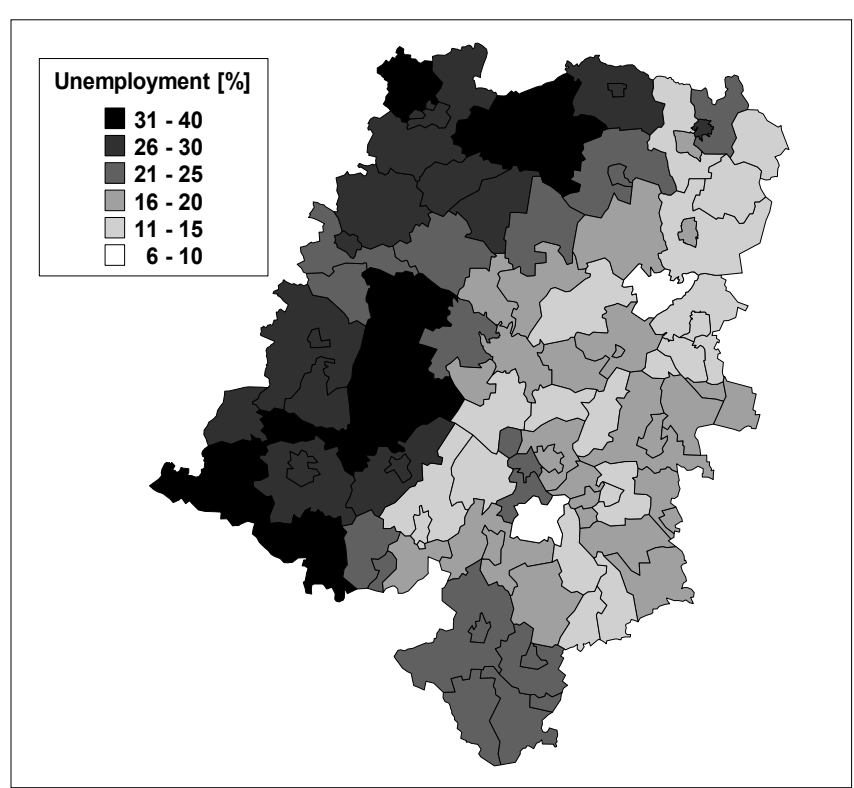

Fig. 2. Unemployment in Opole province (2001).

\section{METHODS}

In the study a fully Bayesian modelling of the data was conducted using Win BUGS 1.4 software (28). The analysis was 


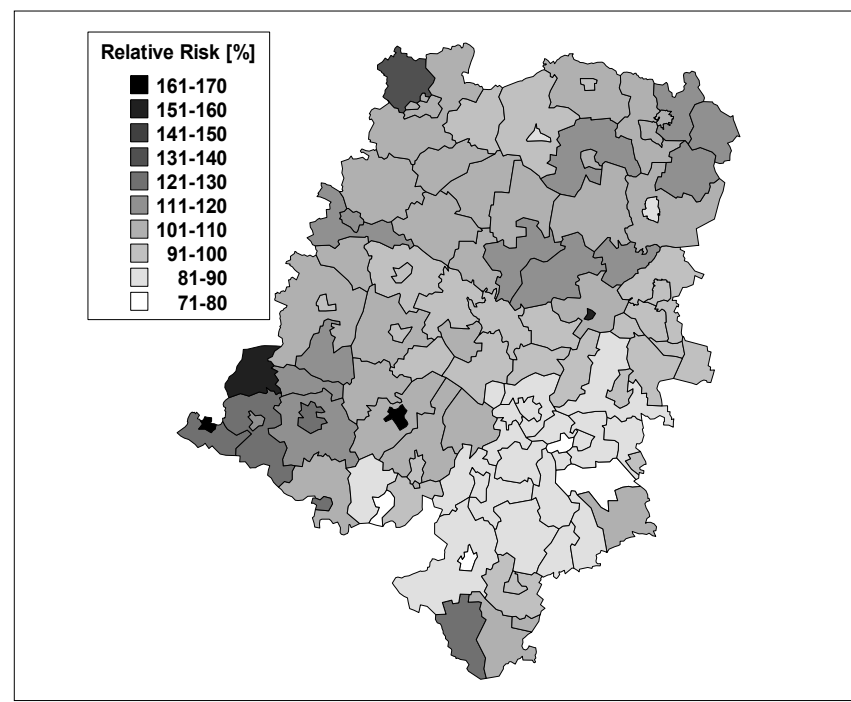

Fig. 3. Congenital malformation's mortality in infants in Opole province (1999-2003).

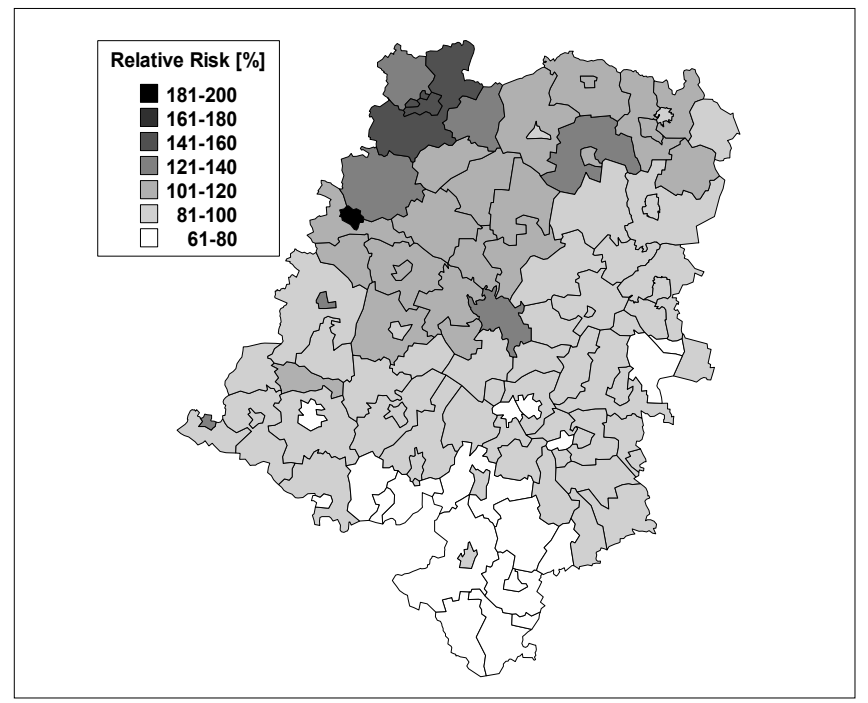

Fig. 4. Premature mortality in infants in Opole province (1999-2003).

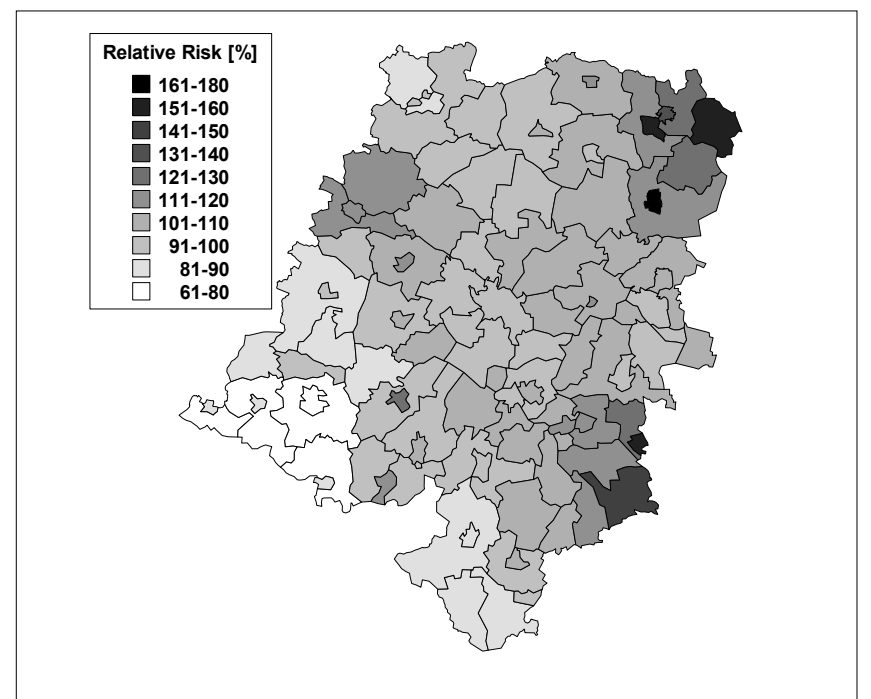

Fig. 5. Infection mortality in infants in Opole province (1999-2003). based on the random-effects Poisson regression - the conditional autoregressive model and the relative risk (RR) for the mortality was estimated following the example of (28).

The computation based on a burn-in of 1000 iterations and following a production-run of 10,000 samples provided convincing evidence of converged distributions of the streams of values during the Gibbs sampling.

Then, the linear (Pearson's) correlation coefficients between the modelled RRs for early mortality in infants and the analyzed (health care and socioeconomic) variables were estimated.

\section{RESULTS}

The spatial pattern of the relative risk for mortality in infants from the congenital malformations in Opole province is showed in Fig. 3.

From the spatial distribution exposed in Fig. 3 it can be seen that the elevated RRs for mortality from congenital abnormalities are observed mainly at the edges of the region (the highest risks are noticed in the south-western communes), while the lowest ratios are characteristic for the south-eastern and central territories.

The spatial model of neonatal and post neonatal premature mortality presented in Fig. 4 indicates a much more clustered pattern of risk levels across the province.

The elevated RRs for early premature mortality (Fig. 4) is observed in the north-western part of the region, whereas the remaining territories (especially the southern part) demonstrate the lower risk.

The risk for the infection mortality in infants in Opole province is presented in Fig. 5.

From the map in Fig. 5 it can be seen (with small exceptions) a clear geographical division of the risk in the region, i.e. the mortality levels are higher in the eastern parts, while the west of the province is characterized by the lower chances.

The spatial model of the sudden infant death syndrome (Fig. 6) indicates medium risk throughout Opole province.

It is notable, however, that the highest RRs for SIDS have been modelled in the four towns located close one to another:

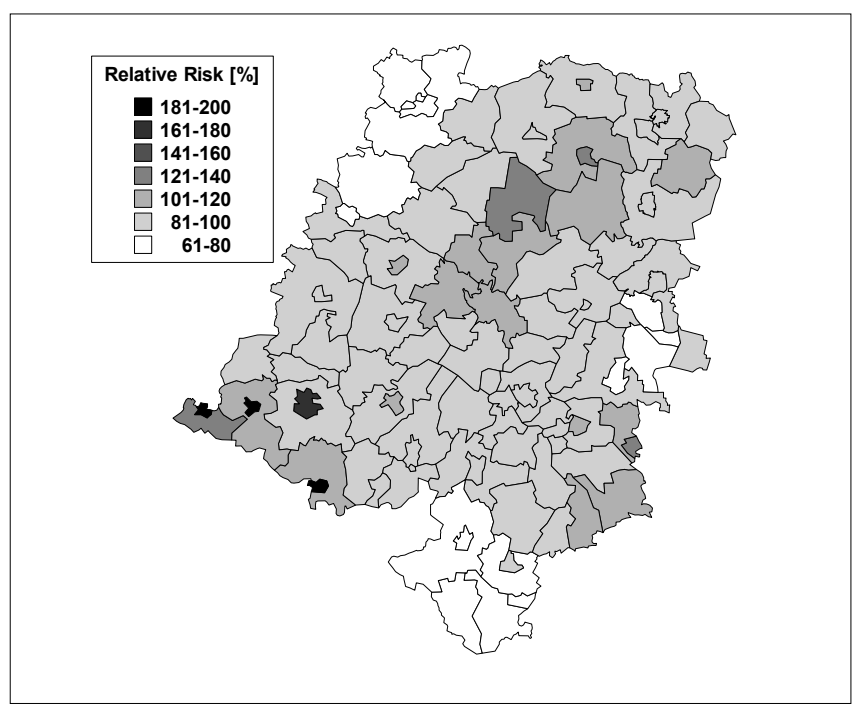

Fig. 6. Sudden infant death syndrome mortality in Opole province (1999-2003). 


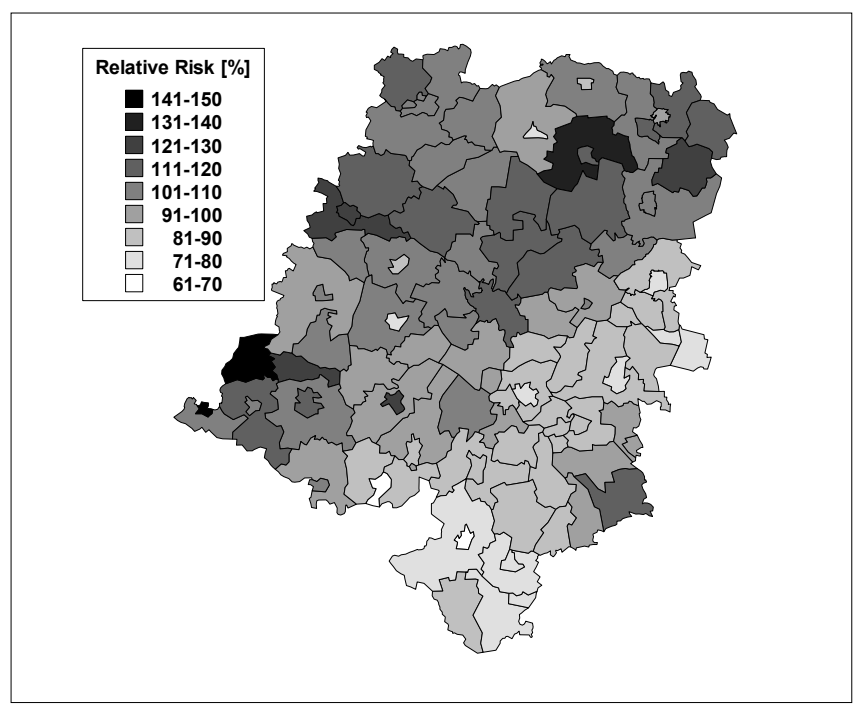

Fig. 7. Infant (neonatal and post neonatal) mortality (all groups combined) in Opole province (1999-2003).

Paczków, Otmuchów, Głuchołazy, and Nysa (south-western part of the province - Fig. 6) of the state boundary area.

The distribution of the relative risk for the neonatal and post neonatal mortality (all groups combined) is presented in a spatial model in Fig. 7.

The map in Fig. 7 testifies a fairly mosaic pattern of mortality across the region and it is consistent with the modelled risk for the congenital malformation's mortality (compare with Fig. 3).

The Pearson's correlation coefficients between the modelled infant mortalities and the analyzed health care and socioeconomic variables are shown in Table 3.

From the coefficients set in Table 3 it can be stated that there is no significant correlation between the neonatal plus post neonatal mortality in infants and the health care provided (gynaecologists' ratio) in Opole province. Whereas, the mortality is strongly related to the socioeconomic situation (unemployment rates) in the region, i.e. the worse unemployment level, the more risk for infant mortality from congenital malformations, prematurity, SIDS, and all groups combined. Surprisingly, an adverse effect is observed for the mortality caused by infections (see Table 3 for details).

\section{DISCUSSION}

We presented an ecological analysis of infant mortality in healthcare and socioeconomic aspects using the so-called ecological variables, i.e. gynaecological doctor ratio and unemployment. A geographical representation of a relative risk according to death causes testifies considerable diversity in mortality rates throughout the province of Opole in the analyzed period. The spatial models of mortalities from the congenital malformations and for the all groups combined prove evidence rather of a mosaic distribution of these risks, whereas the patterns for the mortalities caused by the prematurity, SIDS, and infections were more clustered.

It may be noted that linear correlation analysis surprisingly indicated no influence of the health care provided (represented by the gynaecological doctor ratio per 1,000 women in reproductive age) on the infant mortality in the region. This fact thus denies the possible effect of the worse gynaecological medical infrastructure on neonatal and post neonatal deaths, and vice versa (all the estimated Pearson's correlation coefficients are insignificant). However, due to centralization of the neonatal and paediatric health care for infants this relation cannot be evaluated in this study.

At the same time, the unemployment rate for the given communes (expressed in percentage) treated in the research as the determinant of the economic level of the people living in the region, occurred as a factor strongly influencing the mortality of infants. The achieved data concerning death causes in total as well as other causes, except for infections, have been expected and confirm the earlier cited reports and observations. They indicate that low social and economic status may be a vital factor in increasing the risk of pregnancy complications, including congenital malformations, prematurity, sudden infant death syndrome, and all groups combined.

\section{CONCLUSIONS}

In so far, the general conclusion from this study could be as follows: the levels of the risk for neonatal and post-neonatal mortality did not result in the gynaecological healthcare disproportion supply in the province of Opole. Because of the unemployment causing a poor socioeconomic situation, pregnant women paid more attention to improve their living conditions, than to an adequate medical consultation. Some social dysfunctional factors might play a role in the explanation of the risk of infant mortality.

The observation which is worth mentioning is a negative correlation between the low unemployment and the frequency of infection-related deaths. The following scenario is taken into consideration: in the high economic status sub-regions pregnant women more often visit gynaecologists, they more often undergo gynaecological check-ups and, as a result, this can be the reason for the increase in transmission of foetal infections. However, further research needs to be carried out to prove such a relationship exists and also to find other factors.

Table 3. Linear correlations between the infant mortalities and the analyzed health care and socioeconomic variables

\begin{tabular}{|l|c|c|c|c|c|}
\hline & $\begin{array}{c}\text { Congenital } \\
\text { malformations }\end{array}$ & Prematurity & Infections & SIDS & All groups combined \\
\hline Health care & -0.0453 & -0.0745 & -0.0897 & 0.1011 & -0.0698 \\
level (doctor ratio) & $p=0.651$ & $p=0.457$ & $p=0.370$ & $p=0.312$ & $p=0.486$ \\
\hline Socioeconomic status & 0.3619 & 0.3529 & -0.4074 & 0.2566 & 0.3084 \\
(unemployment) & $p<0.001$ & $p<0.001$ & $p<0.001$ & $p=0.009$ & $p=0.002$ \\
\hline
\end{tabular}




\section{Acknowledgements}

We would like to thank the anonymous Referee for the very constructive comments on an earlier draft.

\section{REFERENCES}

1. Dollfus C, Patetta M, Siegel E, Cross AW. Infant mortality: a practical approach to the analysis of the leading causes of death and risk factors. Pediatrics. 1990 Aug;86(2):176-83.

2. Kempe A, Wise PH, Wampler NS, Cole FS, Wallace H, Dickinson C, et al. Risk status at discharge and cause of death for postneonatal infant deaths: a total population study. Pediatrics. 1997 Mar;99(3):338-44.

3. Miller HC. Analysis of fetal and neonatal deaths in 4117 consecutive births. Pediatrics. 1950 Feb;5(2):184-92.

4. Hessol NA, Fuentes-Afflick E. Ethnic differences in neonatal and postneonatal mortality. Pediatrics. 2005 Jan;115(1):e44-51.

5. Mansfield CJ, Wilson JL, Kobrinski EJ, Mitchell J. Premature mortality in the United States: the roles of geographic area, socioeconomic status, household type, and availability of medical care. Am J Public Health. 1999 Jun;89(6):893-8.

6. Martin JA, Kochanek KD, Strobino DM, Guyer B, MacDorman MF. Annual summary of vital statistics - 2003. Pediatrics. 2005 Mar;115(3):61934

7. Kleinman JC, Kiely JL. Postneonatal mortality in the United States: an international perspective. Pediatrics. 1990 Dec;86(6 Pt 2):1091-7.

8. Kulkarni P, Hall RT, Rhodes PG, Sheehan MB. Postneonatal infant mortality in infants to a neonatal intensive care unit. Pediatrics. 1978 Aug;62(2):178-83.

9. Vrijheid M, Dolk H, Stone D, Abramsky L, Alberman E, Scott JE. Socioeconomic inequalities in risk of congenital anomaly. Arch Dis Child. 2000 May;82(5):349-52.

10. Khoshnood B, De Vigan C, Vodovar V, Goujard J, Lhomme A, Bonnet D, et al. Trends in prenatal diagnosis, pregnancy termination, and perinatal mortality of newborns with congenital heart disease in France, 1983-2000: a population-based evaluation. Pediatrics. 2005 Jan;115(1):95-101.

11. Leach CE, Blair PS, Fleming PJ, Smith IJ, Platt MW, Berry PJ, et al.; CESDI SUDI Research. Epidemiology of SIDS and explained sudden infant deaths. Pediatrics. 1999 Oct;140(4):e43.

12. Newman RD, Grupp-Phelan J, Shay DK, Davis RL. Perinatal risk factors for infant hospitalization with viral gastroenteritis. Pediatrics. 1999 Jan;103(1):e3.

13. Guildea ZE, Fone DL, Dunstan FD, Sibert JR, Cartlidge PH. Social deprivation and the causes of stillbirth and infant mortality. Arch Dis Child. 2001 Apr;84(4):307-310.
14. Sazawal S, Black RE, Menon VP, Dinghra P, Caulfield LE, Dhingra U, et al. Zinc supplementation in infants born small for gestational age reduces mortality: a prospective, randomized, controlled trial. Pediatrics. 2001 Dec;108(6):1280-6.

15. Chen A, Rogan WJ. Breastfeeding and the risk of postneonatal death in the United States. Pediatrics. 2004 May;113(5):e435-9.

16. Parashar UD, Kilgore PE, Holman RC, Clarke MJ, Bresee JS, Glass RI Diarrheal mortality in US infants: influence of birth weight on risk factors for death. Arch Pediatr Adolesc Med. 1998 Jan;152(1):47-51.

17. Humphrey JH, Agoestina T, Wu L, Usman A, Nurachim M, Subardja D, et al. Impact of neonatal vitamin A supplementation on infant morbidity and mortality. J Pediatr. 1996 Apr;128(4):489-96.

18. Bergman AB. Synthesis. In: Bergman AB, Beckwith JB, Ray CG, editors. Sudden Infant Death Syndrome. Seattle, WA: University of Washington Press; 1970. p. 210-1.

19. Guntheroth WG, Spiers PS. The triple risk hypotheses in sudden infant death syndrome. Pediatrics. 2002 Nov;110(5):e64.

20. Opdal SH, Rognum TO. The sudden infant death syndrome gene: does it exist? Pediatrics. 2004 Oct;114(4):e506-12.

21. Kerr JR, Al-Khattaf A, Barson AJ, Burnie JP. An association between sudden infant death syndrome (SIDS) and Helicobacter pylori infection. Arch Dis Child. 2000 Nov;83(5):429-34.

22. Spiers PS, Guntheroth WG. The effect of the weekend on the risk of sudden infant death syndrome. Pediatrics. 1999 Nov;104(5):e58.

23. Blair PS, Nadin P, Cole TJ, Fleming PJ, Smith IJ, Platt MW, et al. Weight gain and sudden infant death syndrome: changes in weight $\mathrm{z}$ scores may identify infants at increased risk. Arch Dis Child. 2000 Jun;82(6):4629.

24. Malloy MH, Hoffman HJ. Prematurity, sudden infant death syndrome, and age of death. Pediatrics. 1995 Sep;96(3 Pt 1):464-71.

25. Shi L, Macinko J, Starfield B, Xu J, Regan J, Politzer R, et al. Primary care, infant mortality, and low birth weight in the states of the USA. J Epidemiol Community Health. 2004 May;58(5):374-80.

26. Shaw C, Blakely T, Atkinson J, Crampton P. Do social and economic reforms change socioeconomic inequalities in child mortality? A case study: New Zealand 1981-1999. J Epidemiol Community Health. 2005 Aug;59(8):638-44.

27. Honigfeld LS, Kaplan DW. Native American postneonatal mortality Pediatrics. 1987 Oct;80(4):575-8.

28. Spiegelhalter DJ, Thomas A, Best N, Lunn D. WinBUGS [computer program]. Version 1.4. Cambridge: Medical Research Council-Biostatistics Unit; 2002 [cited 2006 Sep 23]. Available from: http://www.mrc-bsu. cam.ac.uk/bugs/welcome.shtml. 